\title{
COVID-19 - Community Based Mitigation Measures
}

\author{
Ankita Motwani ${ }^{1}$, Dr. Swaroopa Chakole ${ }^{2}$ \\ ${ }^{1}$ Intern, Dept. of Community Medicine, Jawaharlal Nehru Medical College, DattaMeghe Institute of Medical \\ Sciences (Deemed to be University), Sawangi (Meghe), Wardha-442001, Maharashtra, India, \\ ${ }^{2}$ Professor, Dept. of Community Medicine, Jawaharlal Nehru Medical College, DattaMeghe Institute of Medical \\ Sciences (Deemed to be University), Sawangi (Meghe), Wardha-442001, Maharashtra, India, \\ emails: ${ }^{1}$ motwaniankita363@gmail.com, ${ }^{2}$ drswaroopachakole@gmail.com \\ Type of Article: Review \\ Conflict of Interest: None \\ Funding: DMIMS \\ Ethical Approval: IEC, DMIMS, Wardha.
}

\begin{abstract}
BACKGROUND

COVID-19 pandemic is raging through continents and creating disturbances in almost all the activities of the human life sustenance. The worst disease outbreak is being faced by the humanity and containment is the need of the hour.

SUMMARY

Community based mitigation can prove game changer as current efforts are totally centralized and are hardly decentralized. Community participation under the supervision of the competent community health or medicine officer or equivalent authority can be ensured to effectively contain the coronavirus and thereby reducing the burden on the health care facilities.
\end{abstract}

\section{CONCLUSION}

More study needs to be done to target the efforts of containing the virus.People's participation along with medical fraternity is the key to successfully defeating the menace of the pandemic of COVID-19.

KEYWORDS: COVID-19, COMMUNITY MEDICINE, COMMUNITY MITIGATION, MUTATION, INFODEMIC, VACCINE.

\section{INTRODUCTION}

Coronavirus disease 2019 or COVID-19 has been the most devastating event after the Second World War. The new member in the coronavirus family, novel coronavirus which already caused chaos in 2003 and 2012 in the form of severe acute respiratory syndrome (SARS) and middle eastern respiratory syndrome (MERS), has now came up with new disease that is COVID19. The crown shaped, spike protein containing virus is extremely virulent and deadly.(1) After the origination in Wuhan city if the Hubei province of Asian country of China, it has spread its tentacles to almost every part of the globe affecting each and every inhabitant of the earth, one way or the other. As of January 3, 2021, infection caused due to COVID-19 stands at84,644,904 and case fatalities crossed one and half million mark touching the figure of 1,837,138.(2). This much casualties are attached to COVID-19 related complications. The high uncertainty attached to the virus's behavior makes it difficult to project its trajectory. As of now, United States of America, India, Brazil, Russian federation, France and United Kingdom are the top six countries accounting for nearly more than half of the total infection and more than casualties attached to COVID19(3). The recent occurrence of infection caused due to new mutated strain of the coronavirus from United Kingdom and South Africa is a cause of concern(4). Also the new strain is supposedly seventy percent 
more virulent than its previous counterpart although no study has been published in support of the said argument(5). Comorbidity is the biggest decider in the clinical outcome of the patient(6). The fact that it outnumbers any event in the past century human history in termsof casualties caused by any disease outbreak. Containment of the virus is a difficult task due to its virulent nature and unpredictable behavior. Various models are being tried out one of which is community based mitigation measures. Coercive measure has good and bad things at par so there is a need of measures voluntarily adopted which may also prove beneficial than the former one. Social distress can also be dealt with dedicated team of community health officers and mental health expert in order to resolve any query and comfort the aggrieved party. In this article we are going to assess the benefits of community based interventions in the wake of COVID-19 pandemic(7).

\section{COMMUNITY MITIGATION IN COVID-19}

As the COVID-19 or the coronavirus disease 2019 has been proving lethal among all disease outbreaks in the past century. In fact the figure of human casualties in a particular year is one of the highest for all times especially due to disease outbreaks. The extreme virulent nature and high mortality rate attached to it makes it difficult to control. After the outbreak started in china in Wuhan city, the lockdown measure was first imposed by the same country. As infection spilled over all over the world the same non-pharmacological intervention (NPI) like lockdown and movement restrictions were adopted by the whole world as there were no other mitigatingstrategy was known and various governmental agencies and health care authorities wanted some time to think on possible mitigation measures. This coercive measure has led to confinement of majority of the people at home and other impact such as job loss, loss of livelihood etc.(8). was felt across the world. People were forced to stay at home which was destines to not long last as this was against the human nature. The need of more subtle yet effective measures was felt so that people won't feel coerced or forced to do something to contain the viral spread. Because the viral spread is here to stay for quite a long time even after the arrival of vaccine as vaccination of more than seven billion inhabitants of earth will surely take considerable amount of time and self-restrain is the best restrain. Targeted and more effective intervention can be achieved through community intervention. It can reduce the speed of spreading the infection drastically and have multifold effect. Also people's compliance can be ensured in such scenario. Various measures can be adopted which are non-coercive yet efficient to control the coronavirus spread through the masses. As the lockdown is relaxing in several countries and various events are round thecorner, number of events and gathering may increase. Man is a social animal and it needs to be socialize. But these events and gatherings may prove super spreading events as close contact of the people and no physical distancing can be ensured in these events. Chances of any such viral transmission are high and if controlled can reduce the new infection cases drastically. Public everts such as music concerts, religious ceremonies, marriage gathering, ritualistic gathering, conferences, sports events involves large amount of audiences and participants. Observation of mitigation measure may not be possible in such a crowd. Any type of infection can be transmitted through such crown at a very fast speed resulting into exponential rise in cases in next few days overwhelming the 
local authorities. Two examples from two different countries about can be cited as the effective outcome of the community measures. First case study from kingdom of Saudi Arabia (KSA), where early pilgrimage of Umrah which involves millions of devotees around the world gather in KSA to pay respect to the pilgrimage cite. This year due to coronavirus disease 2019, it was cancelled by KSA authorities whichresulted in lowering of case numbers compared to the scenario where event was given permission to gather. In another case study from Iran, where annual Qom pilgrimage was organized despite the COVID-19 menace in the country as well as around the world. Post event Iran saw massive rise in COVID-19 infection and it was out of control of Iranian authorities. Therefore the efficacy of the community measures can be seen in these two event outcomes. Another such major events like Olympic Games 2020 which were scheduled to be held in Japan was postpones to year 2021, Dubaiexpo, hajj pilgrimage were also postponed due to fear of transmission(9).

not by any fear of punitive measure understand the benefits and follow physical distancing in public places. Close contact at public places can also be transmitting even and can contribute in increasing the number of coronavirus infection cases. The goal of physical distancing basically is to reduce human to human transmission and to break the chain of the disease transmission. Closure of various congregational sites such as schools, colleges, offices, religious and worshipping places, cinema theatres, restaurants and bars where large gatherings of peoples can be expected should either be closed or opened with strict physical restrictions and other obey mitigation measures. Schools and colleges are the most densely habited spaces with almost three to five $\mathrm{m}^{2}$ per person and home indicates approximately 36 to $44 \mathrm{~m}^{2}$ per person. Physical distancing can be easily followed in home as compared to schools and offices. Alternative provision for school going children for education can be made through use of technologies. Office is yet another transmission hotspot where wide range of people work and in shifts resulting into increased chance of the viral transmission. New and dynamic shift with sparse employees working can be a solution if total closure is not feasible.(10)

Travel restrictions across the international borders and within countries must strictly regulated as these are the starting points of any infection. The flights from Wuhan city of the Hubei province of china has proving deadly now due to the then delay in closure of flight services to and from Wuhan. One must travel only if there is dire need to do the same. Also every country can demand negative COVID-19 test results which further can be extended to isolation and quarantine post arrival which will automatically discourage unnecessary travel and reducing the infection case number. Home quarantine must be encouraged so that burden on health care facilities can be reduced. Also sensitive events such as funerals must be held under strict vigilance oh health authorities with minimum number of people in order to minimize the risk of transmission.(11)

Community mitigation may also include keeping oneself safe from the infection by various measures. This may include wide varieties of the mitigation measures at personal levels. From wearing masks, physical distancing to eating foods with high immunity boostingingredients, these measures at personal levels and promoting the same at national levels may be effective in containing the viral spread. Properly wearing masks may itself is a service to nation as improper usage of mask has been 
linked to false sense of society and rise in number of infection cases of COVID-19. Physical distancing is hard to follow but one has to keep in mind that unprecedented situation requires measures at par with that situation to override the situation. Immunity is the keyword that has been doing rounds as people with comorbidities has been affected the most. The comorbidity of any type weakens the immune system of the body and can reduce the fighting response of the body against the external pathogenic invasion. Various dietary habits are proven to be effective in boosting the immunity in general which protects the body from any such viral infection. Vitamin $\mathrm{C}$, vitamin $\mathrm{D}$, probiotics and many such foods containing these content has been proven to be effective in various vital functioning of the body. For example Vitamin $\mathrm{C}$ is meant to generate the anti-inflammatory and antioxidant response which is most needed in the COVID-19 pandemic(12). Vitamin D has strong association with the immune response and is directly linked to the chances of COVID-19 infection if the deficiency is found in person concerned. Gut health and lung health is directly attached as ones degradation means the others reduction in capacity. The gutlung axis is also meant to be playing as decider for developing of type of symptom duringtreatment. Gut microbiota is essentiallyhelpful in absorbing various nutrients and good substances from the food intake. Therefore maintain good gut microbiome ecosystem may prove beneficial in warding off the COVID-19 infection. Food containing these substances can be included in the diet. Otherwise supplements containing these contents may also consumed in order to maintain the minimum essential levels of these contents. This is the pre infection usage also known as prophylactics. Post infection when person is undergoing treatment of COVID-19, these prophylactics can now act as a treatment course supplementary material. As in COVID-19 the oxidative stress of the body is increased manifold(13). This can hamper the functioning of the body in negative way. Vitamin $\mathrm{C}$ is a natural anti-oxidant which helps in reducing the oxidative stress and boost the functions of the various body organs. Inflammation is yet another bad byproduct of the COVID-19 infection and which can be done away with the supplements of vitamin D. Vitamin D is known to induce anti-inflammatory properties and helps in containing the inflammation that is occurring due to various infection(14).

\section{TECHNOLOGY AND COMMUNITY MITIGATION MEASURES}

Community mitigation has various aspects attached to it which can be used to achieve larger public good. Technology with public participation is one of them. We are already experiencing digital revolution and every person is exposed to so much technology that can be used in either ways. Various community measures if coupled with existing measures can prove extremely efficient and useful in tackling COVID-19 menace. Taking a small example of airports. As economies are opening up, borders are starting to open more people are eager to travel with their various chores. In the COVID-19 scenario the more people gather at one place, the more they are vulnerable to catch the infection. Crowd can be formed at lounge in the airports and driveway. If this is not managed properly more infection can be reported throughout the world. Also the newly arrived strain of the novel coronavirus post mutations supposedly seventy percent more virulent than the previous strain. Chances of cross border of this strain may be facilitated by crowds at airports or any other transport hub. With technology some 
airports has introduced digital queue management system. Basically the passenger is warned about his or her number at boarding get, till then he or she have to wait in a designated area. Also two passenger getting closer can trigger alarm and physical distancing is maintained. This is the good way of using the technology for the containment of the disease. This measure can be employed at railway station, bus station, shops and various other stores and places where large congregation is expected. If through application the user can be intimated about his number at the queue then the chance of physical closeness can be reduced and hence the chance of transmission will also be reduced(15).

As the pandemic has started in the start of the year 2020, very little was known about its existence, its behavior and various other things. This has also created massive transfer and reception of misinformed messages across various social media networks, deliberately or non-deliberately, creating confusion among masses. Some anti-socialelements in the society tried to run some disinformation campaign,sometimes for fun,sometimes for hidden motives. The message content emotionally exploits the reader and if the reader is not digitally literate means he or she does not know about such misinformation campaign then chances of getting tricked by such messages may be higher. After seeing the extent of the situation the World Health Organization (WHO) declared such evets as Infodemic(16). It is the combination of Information and pandemic. A misinformation or disinformation campaign running parallel to the pandemic.Various messages are circulating about the possible cure of the COVIID-19, false testimonials from the bogus patients about the treatment course, fake news about doctors exploiting patients and so many more. These messages spread with more speed than wildfire. As the penetration of the smartphones and internet is like never before, reaching millions and millions of people with one click is possible in few seconds. Quackery and fake medicine can prove extremely fatal if not checked properly and consultation with the doctor at every stage of the treatment is necessary. Taking medicine or any kind of drugs on our own can prove fatal as various contraindications have tobe taken into account before administering any drugs on patient. Proper diagnosis is therefore required. As the vaccine is in the last stage of the development, various messages about fake ill effects after vaccination has been started to circulate. This can induce vaccine hesitancy and can prove tedious task to vaccinate people. Timely interventionis the key in this process. Counter misinformation campaign needs to be launched at same vigor thereby dispelling myths. Disseminating the authentic messages through community based centers can be reliable and few trusted people can be designated as Infodemic warrior to bust the every myth attached to the COVID-19 which can have dire consequence if left untreated. Community officers can bedesignated to verify any myths beforeacting on it. Also beforehand demystification of the misinformation can be done in order to be one step ahead of such anti-social elements who generate such nuisance message. Regular television, social media, radio, newspaper coverage can be given to the fake news which has made through the week. Educating people and making them digitally literate can also be anoption as it will be helpful not only in current scenario but also in future as technology is here to stay for quite a while(17). 


\section{COMMUNITY MITIGATION OF} PSYCHOLOGICAL DISTRESS

COVID-19 has affected people not only physically or financially, it also hit hard psychologically on the people's mental state. Widespread prevalence of the psychological and social distress was common and needed much attention than it is given now. As the lockdown was announced allacross the world as a mitigating measure to contain the vital spread of the coronavirus due to less information available about how to contain the virus, many jobs were lost and livelihood were destroyed at one go. People were left clueless and vulnerable and thinking about how they can get to eat. Fear of getting contracted with the virus was on another level and this has created huge social panic and anxiety. Home confinement due to lockdown and movement restrictions also added to the woes and people were not able to meet their family members and loved ones. Infected persons were isolated and were experiencing loneliness as they are isolated to due to high virulent nature of the coronavirus. Man is a social creature and need human contact to feel secure $(18,19)$. As the isolation does not allow families to even the entire hospital or COVID-19 care facility premises due to high virulent nature, anxiety was naturally induced. This has to be dealt with a proper psychological strategy as comforting the person and assuring them of positive outcome can be helpful in such situations (20-23). The social distress can be easily dealt by community based measures. Each COVID-19 care facility can be hiring some psychiatrist, mental health expert to deal with the situation. As even doctors appointed for treating COVID-19 patients were under severe mental pressure as they fear of transmitting the virus to their loved ones affecting their efficiency and physical state (24-26). Indigenous measures to combat inection were reported (27-29).
Community health expert can converse with the infected person's families about the situation via a telephone. Also arranging video calls from the COVID-19 ward can be a best way to securing both the patient as well as family member from the deterioration of the situation and having chat with the family members. Each geographical unit have community health officer to address the queries of the people residing in that area(19).

\section{CONCLUSION}

Non-coercive measures adopted by the people as a whole serves the best in mitigating the calamity like the COVID-19 pandemic. Various best practice needs to be popularize under the watch of local community health and medicine officer so as to ensure safe outcomes. Social distress and psychological panic is bound to arise and dedicated team can be the best solution regarding this situation. Infodemic is the parallel pandemic and one has to deal with this on war footing. Or else be ready to face dire consequences arising out of the Infodemic. Cooperation from wider social strata of the society such as nongovernmental organization and civil society groups may ensure larger positive outcomes, lowering burden on already stressed public resources. Awareness about the best practices is the key to effectively contain the coronavirus spread. Fighting COVID-19 with more than sevenbillion people as a unit will only reap benefits in defenestrating the virus from the society.

\section{REFERENCES}

1. Dushyant Bawiskar, Pratik Phansopkar, Ayurva Vilas Gotmare. COVID-19 Facets: Pandemics, Curse and Humanity. Int J Res Pharm Sci. 2020 Aug 6;11(SPL1):385-90. 
2. COVID-19 Map [Internet]. Johns Hopkins Coronavirus Resource Center. [cited 2021 Jan 3]. Available from: https://coronavirus.jhu.edu/map.html

3. WHO Coronavirus Disease (COVID19) Dashboard [Internet]. [cited 2021 Jan 3]. Available from: https://covid19. who.int

4. Wise J. Covid-19: New coronavirus variant is identified in UK. BMJ [Internet]. 2020 Dec 16 [cited 2020 Dec 23];371:m4857. Available from: https://www.bmj.com/content/371/bmj. $\mathrm{m} 4857$

5. CDC. Coronavirus Disease 2019 (COVID-19) [Internet]. Centers for Disease Control and Prevention. 2020 [cited 2021 Jan 3]. Available from: https://www.cdc.gov/coronavirus/2019 -ncov/more/scientific-brief-emergingvariant.html

6. Guan W-J, Liang W-H, Zhao Y, Liang H-R, Chen Z-S, Li Y-M, et al. Comorbidity and its impact on 1590 patients with COVID-19 in China: a nationwide analysis. Eur Respir J. 2020;55(5).

7. The Lancet null. India under COVID19 lockdown. Lancet Lond Engl. 2020 25;395(10233):1315.

8. COVID-19 will hit the poor hardest. Here's what we can do about it [Internet]. [cited 2020 Dec 30]. Available from: https://blogs.worldbank.org/voices/covi d-19-will-hit-poor-hardest-heres-whatwe-can-do-about-it

9. Lyu W, Wehby GL. Community Use Of Face Masks And COVID-19: Evidence From A Natural Experiment Of State Mandates In The US. Health Aff Proj Hope. 2020 Aug;39(8):141925.

10. Ebrahim SH, Ahmed QA, Gozzer E, Schlagenhauf P, Memish ZA. Covid-19 and community mitigation strategies in a pandemic. BMJ [Internet]. $2020 \mathrm{Mar}$ 17 [cited 2021 Jan 1];368:m1066. Available from: https://www.bmj.com/content/368/bmj. m1066

11. Khanna RC, Cicinelli MV, Gilbert SS, Honavar SG, Murthy GSV. COVID-19 pandemic: Lessons learned and future directions. Indian J Ophthalmol. 2020 May;68(5):703-10.

12. Feyaerts AF, Luyten W. Vitamin $\mathrm{C}$ as prophylaxis and adjunctive medical treatment for COVID-19? Nutr Burbank Los Angel Cty Calif [Internet]. 2020 [cited 2020 Dec 10];79:110948. Available from: https://www.ncbi.nlm.nih.gov/pmc/arti cles/PMC7381407/

13. Sundararaman A, Ray M, Ravindra PV, Halami PM. Role of probiotics to combat viral infections with emphasis on COVID-19. Appl Microbiol Biotechnol. 2020 Oct;104(19):8089104.

14. Zabetakis I, Lordan R, Norton C, Tsoupras A. COVID-19: The Inflammation Link and the Role of Nutrition in Potential Mitigation. Nutrients. 2020 May 19;12(5).

15. Queue Management news [Internet]. Future Travel Experience. [cited 2021 Jan 3]. Available from: https://www.futuretravelexperience.co $\mathrm{m} /$ tag/queue-management/

16. Nations U. UN tackles 'infodemic' of misinformation and cybercrime in COVID-19 crisis [Internet]. United Nations. United Nations; [cited 2021 Jan 3]. Available from: https://www.un.org/en/un-coronaviruscommunications-team/un-tackling$\%$ E2\%80\%98infodemic\%E2\%80\%99misinformation-and-cybercrime-covid19 
17. COVID-19 Facets: Pandemics, Curse and Humanity | International Journal of Research in Pharmaceutical Sciences [Internet]. [cited 2020 Oct 17]. Available from: https://pharmascope.org/ijrps/article/vi ew/2731

18. Blake H, Bermingham F, Johnson G, Tabner A. Mitigating the Psychological Impact of COVID-19 on Healthcare Workers: A Digital Learning Package. Int J Environ Res Public Health. 2020 26;17(9).

19. Gualano MR, Lo Moro G, Voglino G, Bert F, Siliquini R. Effects of Covid-19 Lockdown on Mental Health and Sleep Disturbances in Italy. Int J Environ Res Public Health [Internet]. 2020 Jan [cited 2020 Oct 16];17(13):4779. Available from: https://www.mdpi.com/16604601/17/13/4779

20. Bakshi, S., V. Toshniwal, A. Agrawal, S. Acharya, and S. Shukla. "Awareness and Psychosocial Effects of Covid-19 Pandemic on Health Care Professionals and Medical Students across the State of Maharashtra." International Journal of Current Research and Review 12, no. 22 Special Issue (2020): S-122-S125.

https://doi.org/10.31782/IJCRR.2020.S P74.

21. Balsara, K., and D. Shukla. "Stepping up Detection, Response, Preparedness and Readiness Measures for 'Covid-19'-a Pandemic." International Journal of Research in Pharmaceutical Sciences 11, no. Special Issue 1 (2020): 1042-47. https://doi.org/10.26452/ijrps.v11iSPL1. 3442.

22. Bawari, H., and J.N. Chaple. "Covid-19 and the Aching World." International Journal of Research in Pharmaceutical Sciences 11, no. Special Issue 1 (2020):
253-58.

https://doi.org/10.26452/ijrps.v11iSPL1. 2709.

23. Bawiskar, D., P. Phansopkar, and A.V. Gotmare. "Covid-19 Facets: Pandemics, Curse and Humanity." International Journal of Research in Pharmaceutical Sciences 11, no. Special Issue 1 (2020): 385-90. https://doi.org/10.26452/ijrps.v11iSPL1. 2731.

24. Bawiskar, N., A. Andhale, S. Acharya, S. Kumar, and S. Shukla. "Haematological Manifestations of COVID 19 and Their Prognostic Significance-a Cross-Sectional Study." International Journal of Research in Pharmaceutical Sciences 11, no. Special Issue 1 (2020): 918-22. https://doi.org/10.26452/ijrps.v11iSPL1. 3131.

25. Bhatero, D., P. Sawarkar, and G. Sawarkar. "Indian Lifestyle with Ayurveda Perspective during COVID-19 Pandemic." International Journal of Research in Pharmaceutical Sciences 11, no. Special Issue 1 (2020): 1396-99. https://doi.org/10.26452/ijrps.v11iSPL1. 3668.

26. Bhokardankar, P., B. Rathi, M. Khan, and R. Rathi. "COVID-19 Pandemic: Home Remedies for Immunity Boosting." International Journal of Research in Pharmaceutical Sciences 11, no. Special Issue 1 (2020): 734-38. https://doi.org/10.26452/ijrps.v11iSPL1. 3075.

27. Bhutada, R.S., R. Rathi, and D. Dasar. "Immunity Boosting Diet during COVID 19." International Journal of Research in Pharmaceutical Sciences 11, no. Special Issue 1 (2020): 832-38. https://doi.org/10.26452/ijrps.v11iSPL1. 3089. 
28. Biswas, A., and K. Chandankhede. "Dietary and Living Regimen of COVID-19 with Special Reference to Ayurveda Varsha and Sharad Ritucharya." International Journal of Research in Pharmaceutical Sciences 11, no. Special Issue 1 (2020): 758-62. https://doi.org/10.26452/ijrps.v11iSPL1. 3079.

29. Boharupi, G., and P. Shelotkar. "Immunomodulatory Measures to Strengthen the Body during Covid Outbreak." International Journal of Research in Pharmaceutical Sciences 11, no. Special Issue 1 (2020): 774-78. https://doi.org/10.26452/ijrps.v11iSPL1. 3081. 